\title{
DYSPLASIA EPIPHYSIALIS MULTIPLEX
}

\section{A Report of Fourteen Cases in Three Families}

\author{
Roy H. Mat'desey, LoNdon, ENGlayi
}

Senior Orthopaedic Registrar, Royal Free Hospital

This paper reports fourteen cases, in three families, which appear to be examples of dysplasia epiphysialis multiplex, although they differ in some respects from Fairbank's (1946) description.

FAMILY 1

\section{CASE REPORTS}

A boy aged six years attended the Connaught Hospital, London, complaining of pain in the left hip. He was small for his age. Radiographs revealed bilateral "fragmented " epiphyses. Inquiry elicited that several members of his family were similarly affected (Fig. 1).

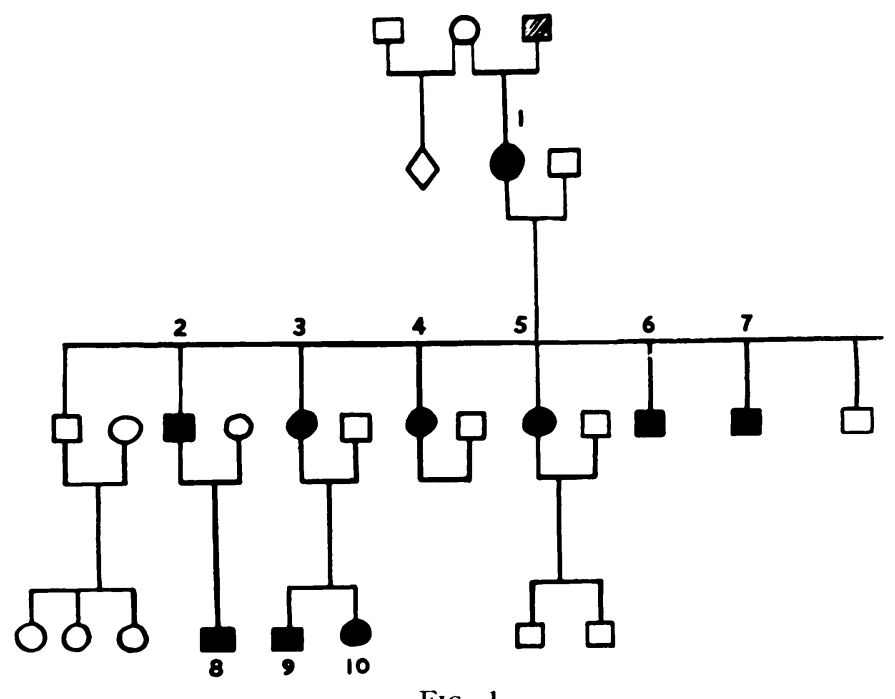

FIG. 1

Family 1. $\quad$ =male; $O=$ female. Black $=$ affected individuals white = unaffected individuals; shaded = unknown if affected Numerals indicate case numbers in this report.

Case 1-Woman aged fifty-eight. She had first noticed pain in her left hip at the age of eleven vears, and this continued until she menstruated at fourteen. Thereafter she suffered only occasional discomfort until a few years ago, when both hips became progressively more stiff and painful and chronic low backache occurred. She has otherwise lived a normal and healthy life, and had eight living children and one stillborn. She never complained of pain or stiffness in other joints. She was the only child of her father, who was " short," but her mother had been married before, and had twelve normal children. She was $4 \mathrm{ft} .7 \mathrm{in}$. in height, had normal intelligence and sexual development, and was a little overweight. When she stood the trunk appeared short and the finger tips reached nearly to the patellae (Fig. 2). There was a mild thoracic kyphosis, with increased lumbar lordosis. She had a waddling gait. At the hips there was 70 degrees of flexion but no other movement. There was some restriction of abduction and medial rotation at the shoulders. All other joints appeared normal. 
Radiographic examination-There were changes in many joints. In both hips osteoarthritic changes were associated with a flattened head, a sloping acetabulum, and coxa vara (Fig. 3). There was slight flattening of the humeral head with an underhanging beak and some irregularity in the glenoid fossa (Fig. 4). The lower tibial epiphysis was sloping, with corresponding changes in the talus, but there was no evidence of osteoarthritis.

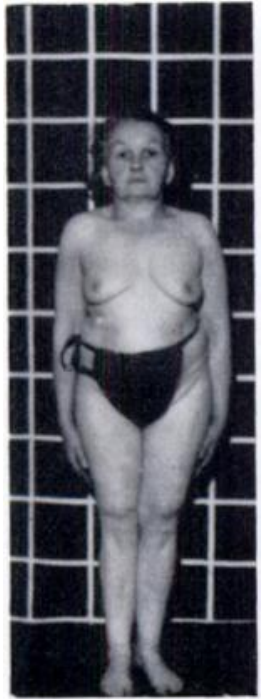

Fac. 2

ase 1 Finure 2-The patient aged fift

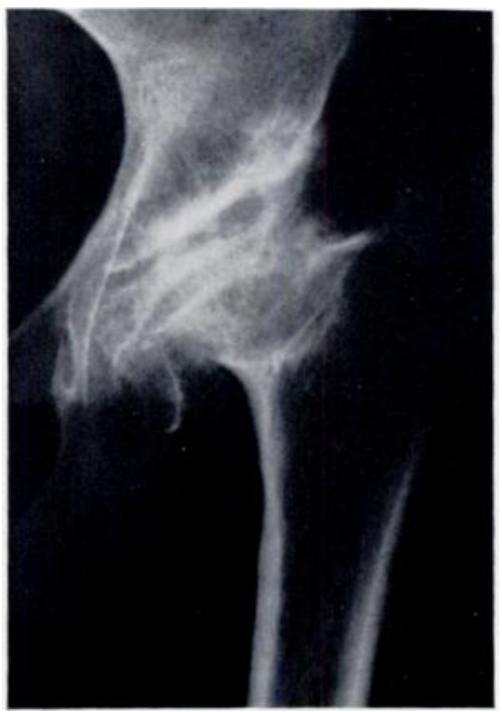

FIG. 3

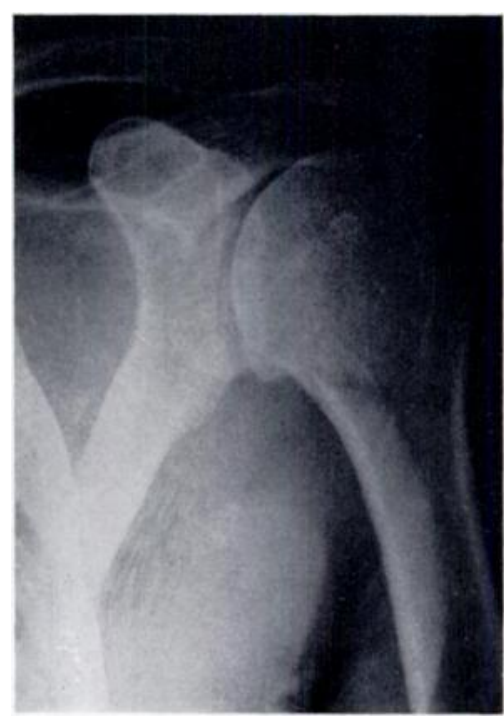

Fili. 4

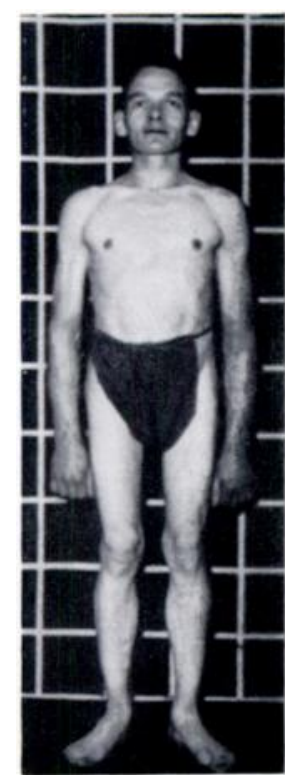

FIG. 5

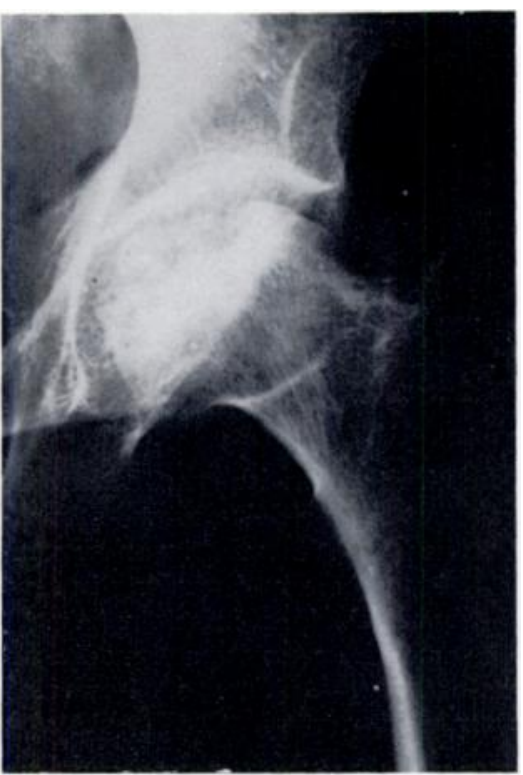

Fig. 6

Case 2. Figure 5 - The patient aged thirty. Figure 6--Left hip.

Case 2 - Man aged thirty, engineer. He was the second son of the patient in Case 1. Though short, he regarded himself as normal. His hip joints felt stiff after prolonged sitting but had never been painful. He was 5 feet in height, with normal intelligence and sexual development. He was very muscular. The trunk appeared short, and the fingers reached to within four inches of the patellae

VW. 37 B, NO. 2, MAY 1955 
(Fig. 5). Flexion at both hips was nearly full but rotation was only half normal. The other joints were normal. The hands and feet looked normal.

Radiographic examination-There were osteoarthritic changes in the hips with irregularity of the femoral heads (Fig. 6). In the left ankle there were sloping articular surfaces. All other joints appeared normal.

Case 3-Woman aged twenty-nine, with two children, both of whom were affected (Cases 9 and 10). She noticed pain in the right hip after her first child was born at the age of twenty-two, but has had no pain since. She could walk five miles without difficulty and did her own housework. Her pregnancies were uneventful. She was $4 \mathrm{ft} .8 \mathrm{in}$. in height. At both hips there was slight reduction of rotation, but other movements were normal. At the shoulder there was slight restriction of medial rotation. There was no carrying angle at the elbows. Hands and feet were normal (Fig. 7).

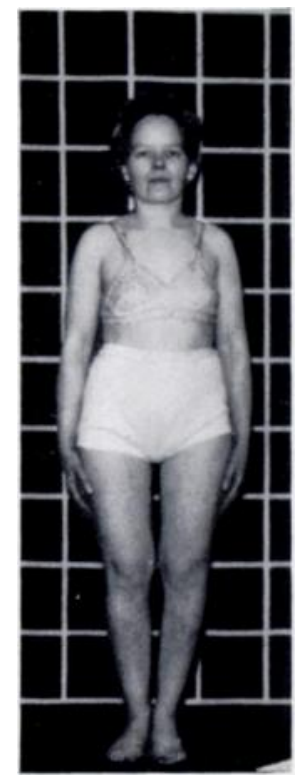

Fig. 7

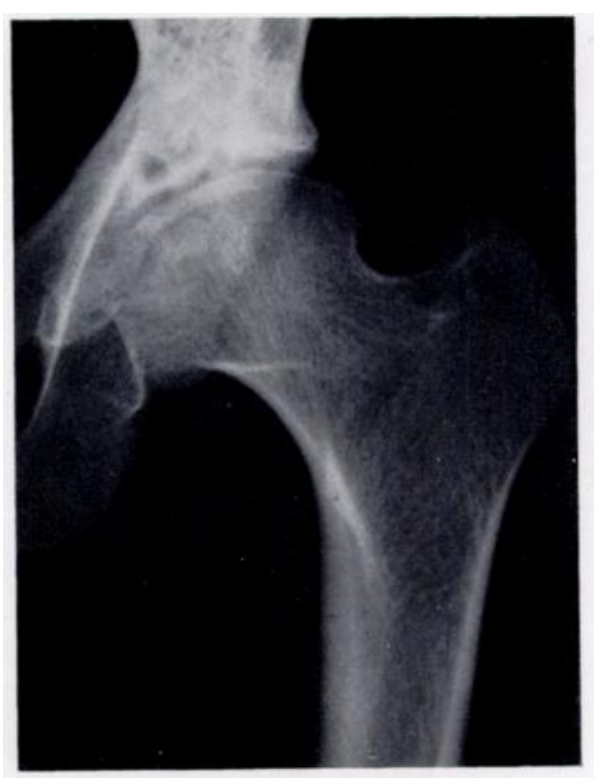

FIG. 8

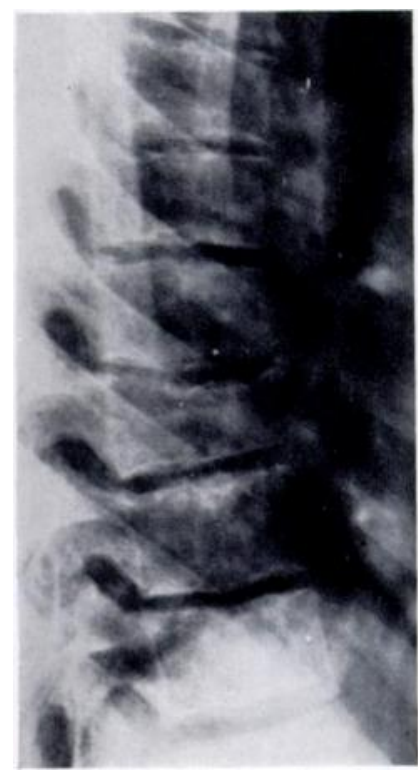

Fig. 9

Case 3. Figure 7-The patient aged twenty-eight. Figure 8-Left hip. Figure 9- Mid-thoracic spine.

Radiographs showed irregularity of the femoral heads, with some flattening (Fig. 8). The shoulders, ankles and knees were normal. The spine showed developmental abnormalities: the thoracic vertebral borders had irregular surfaces, and the body of T.8 was shallow and wedged anteriorly. (Fig. 9).

Case 4-Woman aged twenty-six, with no children. She first noticed pain in her hips when she was twelve years of age, but was able to attend school and work as a domestic servant. For the last three years she has had pain in both hips after exercise, and this has restricted her activities. Five years ago she developed pain and swelling in several joints, and a diagnosis of rheumatoid arthritis was made. She was $4 \mathrm{ft} .4 \frac{1}{2}$ in. in height (Fig. 10). The long axis of the skull was elongated. Hip movements were nearly full, extension and medial rotation only being reduced. Trendelenburg's sign was positive. There was some stiffness of elbows and wrists (possibly from previous rheumatoid arthritis). Other joints were normal. Radiographically', both femoral heads were irregular and flattened; there was marked coxa vara, and the roof of the acetabulum was ill developed (Fig. 11). There was abnormal development of the cervical and thoracic vertebrae (particularly T.5, 6, 7, 9) which were shallow and had irregular surfaces (Fig. 12). There was slight spondylolisthesis at I..5-S.1. The skull showed platybasia (Fig. 13). The lower tibial surfaces were sloping (Fig. 14).

Case 5-Woman aged twenty-four, with two children. In her childhood she had occasional pain in both hips, but subsequently led a normal life, and can still walk five miles. She now has "stiffness" in the hips after exercise or prolonged sitting. She was $4 \mathrm{ft} .11 \mathrm{in}$. in height. There was a nearly full range of movement at both hips. The other joints were normal (Fig. 15). 
Radiographs showed that the right femoral head was flattened medially (Fig. 16). ()therwise the hips showed no marked abnormality. There were mild developmental changes in the thoracic spine, affecting particularly T.6 (Fig. 17).



Fili. 10

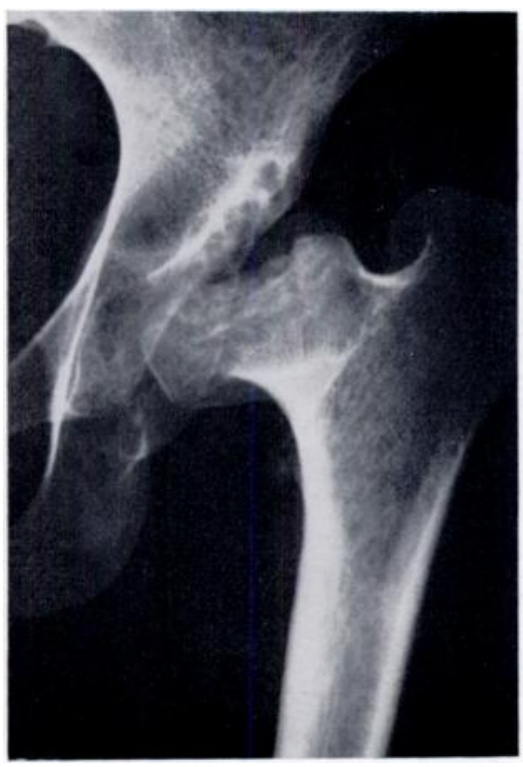

FIg. 11

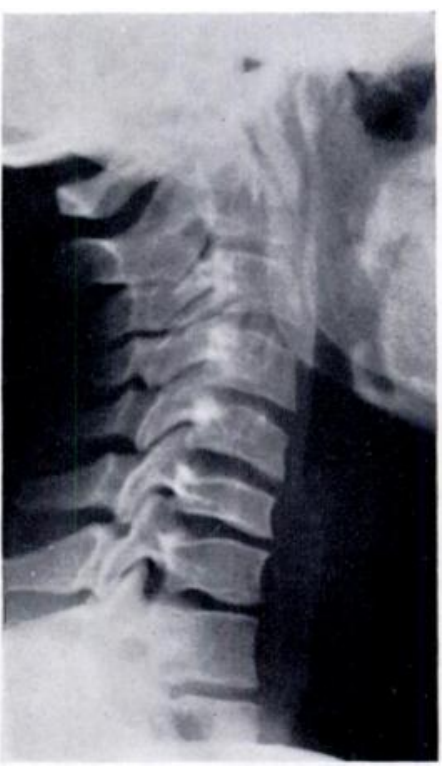

FIG. 12

Case 4. Figure 10-The patient aged twent $v$-six. Figure 11 - Left hip. Figure 12 cervical spine.



FIG. 13



FIG. 14

Case 4. Figure 13-Skull showing platybasia. Figure 14-Ankle joint showing flattened joint surfaces.

Case 6-Man aged twenty-three, colliery surface worker. He had occasional pain in both hips between the ages of five and ten. Recently he complained of pain in both hips after exercise or prolonged sitting. His height was $4 \mathrm{ft}$. $11 \mathrm{in}$. The trunk was short, and the limbs disproportionately long. The fingers reached nearly to the patellae (Fig. 18). Hip movements were slightly restricted,

vol. 37 B, NO. 2 , MAY 1955 
especially rotation on the right side. Radiographs showed that both femoral heads were slightly. flattened and of irregular texture (Fig. 19). The lower tibial surfaces were sloping.

Case 7-Man aged twenty-six, unemployed. He suffered pain in the hips after activity when about seven years old, and could not walk more than a mile because of pain and stiffness. Recently.

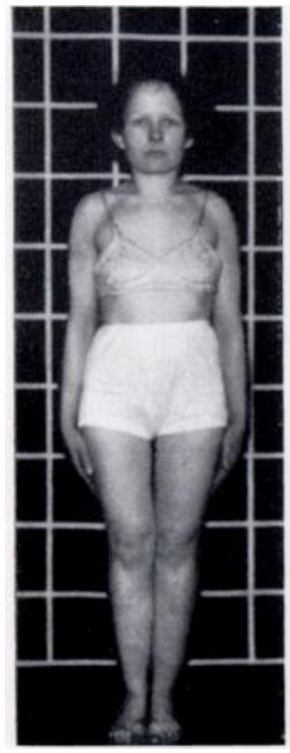

FIG. 15



FIG. 16

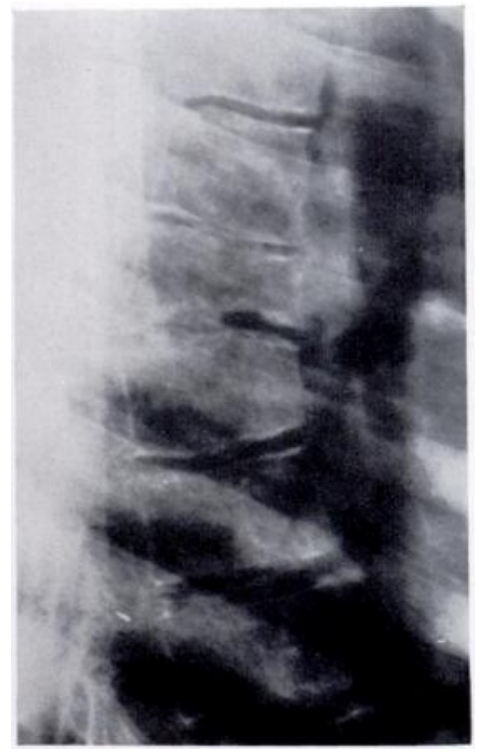

FIG. 17

Case 5. Figure 15-The patient aged twenty-four. Figure 16-Left hip. Figure 17- Thoracic spine.

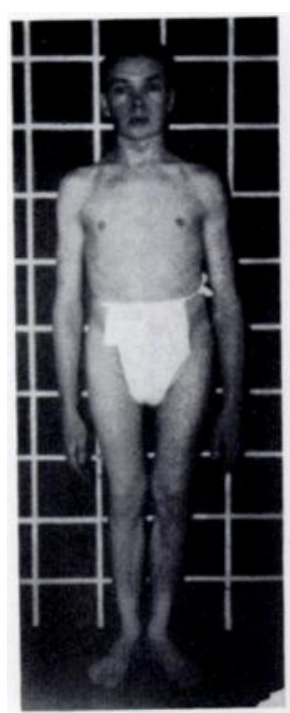

FIG. 18

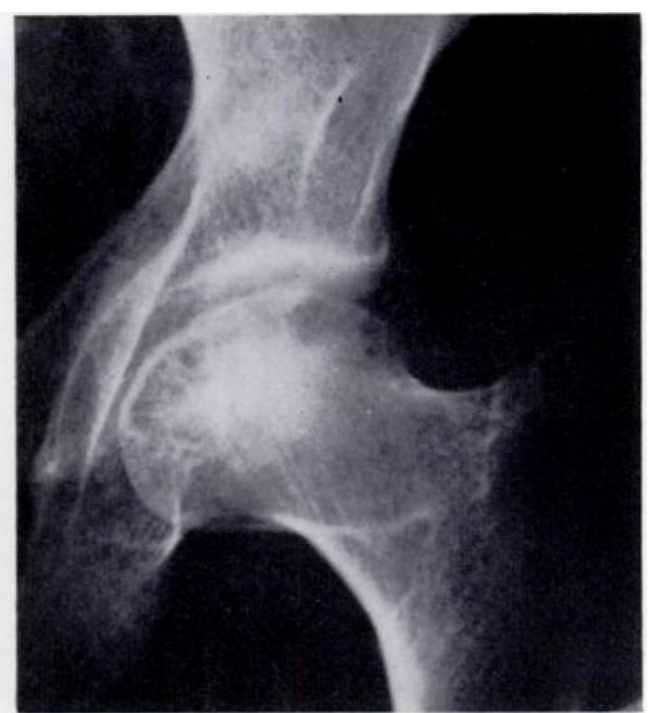

Fig. 19

Case 6. Figure 18-The patient aged twenty-three. Figure 19- Left hip.

he has suffered pain and stiffness in the hips after sitting or walking. His height was $5 \mathrm{ft}$. The arms appeared relatively long and the trunk short. The fingers reached nearly to the patellae (Fig. 20). Movements were restricted at both hips, especially rotation. Radiographically, the femoral heads were flattened and the roofs of the acetabula were more sloping than normal. Mild coxa vara was present (Fig. 21). Other joints were not radiographed. 
Case 8 Boy aged eleven. At six years he developed a limp and pain in the right hip. He was admitted to hospital and traction was applied for a short time. He has since had occasional pain in both hips, and has limped when he was tired. His height was $3 \mathrm{ft} .11 \mathrm{in}$. His fingers reached tw within three inches of the patellae (Fig. 22). Hip movements were nearly full, and all other

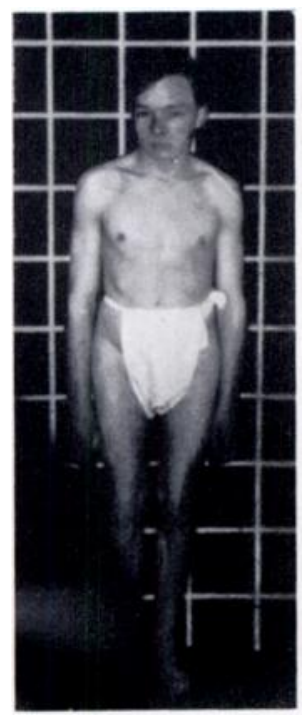

FIG. 20

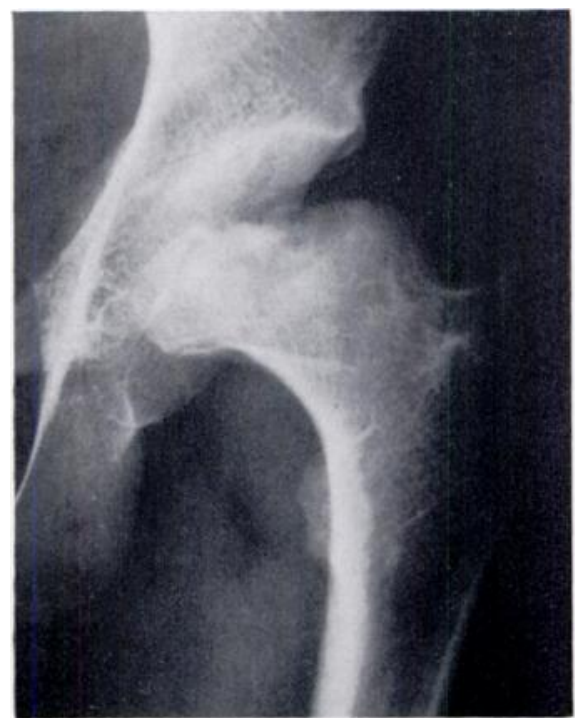

FIG. 21

Case 7. Figure 20 -The patient aged twent $y$-one. Figure 21 - Left hip.

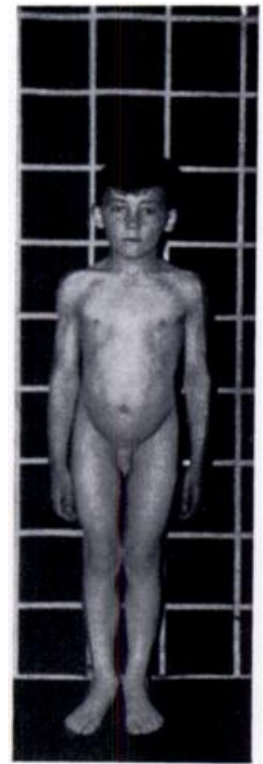

FIG. 22



FIG. 23



FIG. 24

Case 8. Figure 22-The patient aged eleven. Figure 23-Left hip, showing sloping acetabulum and epiphysis for femoral head only just appearing. Figure 24-Left ankle.

joints had a normal range. His hands were normal. Radiographs of the hips revealed sloping acetabula with femoral epiphyses very late in appearing and "fragmented " (Fig. 23). The lateral half of each lower tibial epiphysis was shallow (Fig. 24).

Case 9-Boy aged four years. He had never had pain in his hips, but had walked with a limp

Vol. $37 \mathrm{~B}$, No. 2 , MAY 1955 
when tired. His height was $2 \mathrm{ft} .9 \mathrm{in}$. The upper limbs appeared relatively long, the fingers reaching nearly to the patellae (Fig. 25). There was full mobility of the hip joints. Radiographs showed that in each hip the femoral epiphysis was late in appearing (Fig. 26), and then "fragmented ". and there was broadening of the metaphysis. The acetabula appeared normal. The epiphyses for the upper end of the humeri were slightly fragmented (Fig. 27). The lower tibial epiphyses were slightly shallow laterally (Fig. 28).

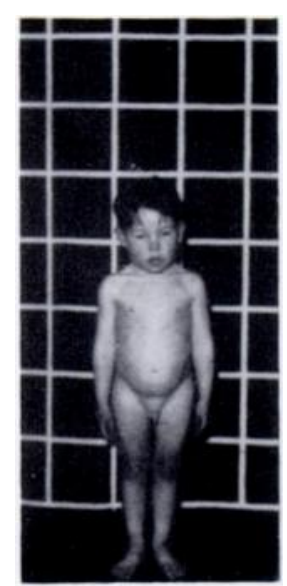

FIG. 25

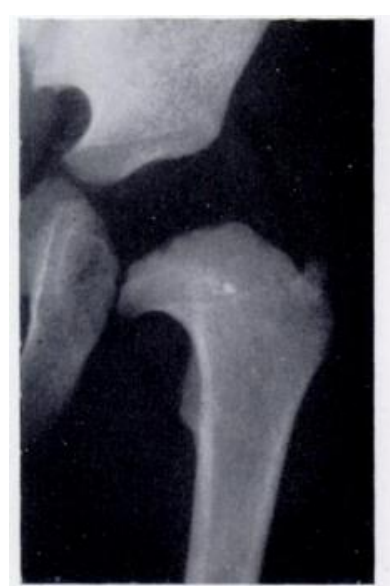

FIG. 26

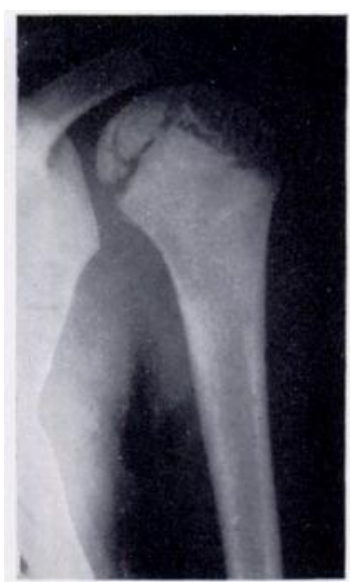

Fig. 27



FIti, 28

Case 9 . Figure 25 - Patient aged four. Figure 26-Left hip. Figure 27 - Left shoulder. Figure $2 \mathrm{~s}$ - L.fft ankle.

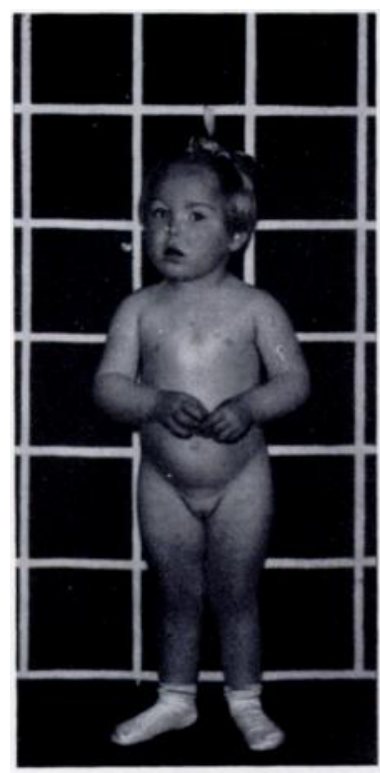

FIG. 29

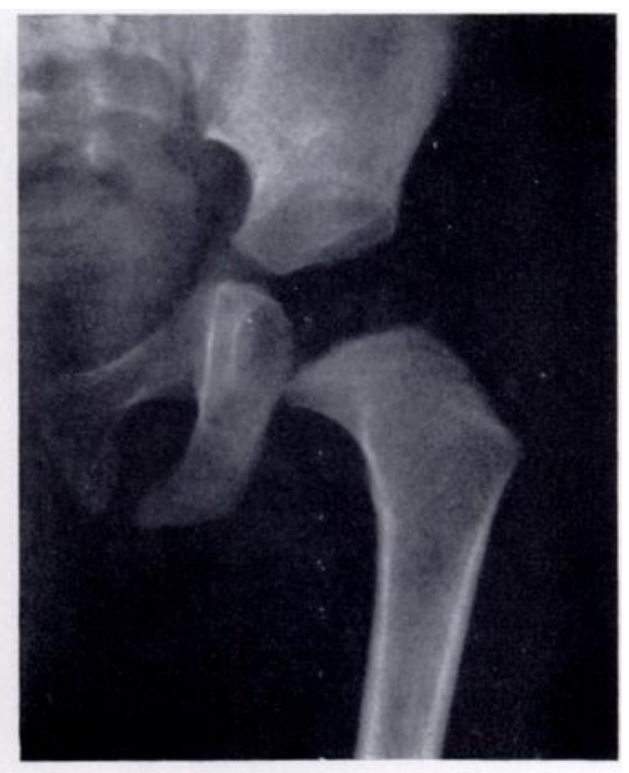

FIG. 30

Case 10. Figure 29-Patient aged three. Figure $30-\mathrm{L}$.eft hip.

Case 10-Girl aged three. At one and a half years she had transient pain in the left hip from which she apparently made a complete recovery. She was small for her age, being $2 \mathrm{ft} .9 \mathrm{in}$. tall (normal $3 \mathrm{ft} .1 \mathrm{in}$.) but otherwise she was of normal appearance (Fig. 29). All joints were clinically normal. Radiographs revealed femoral epiphyses in which irregular ossification produced a stippled epiphysis (Fig. 30). 
FAMILY 2

The patients in Cases 11 and 12 were the youngest of four siblings (Fig. 31). The oldest two were not seen but were stated to be normal and free from the complaints of the others. Both parents were dead. The father was stated to have been tall and the mother short, but there was no history of pain in the hips in either.

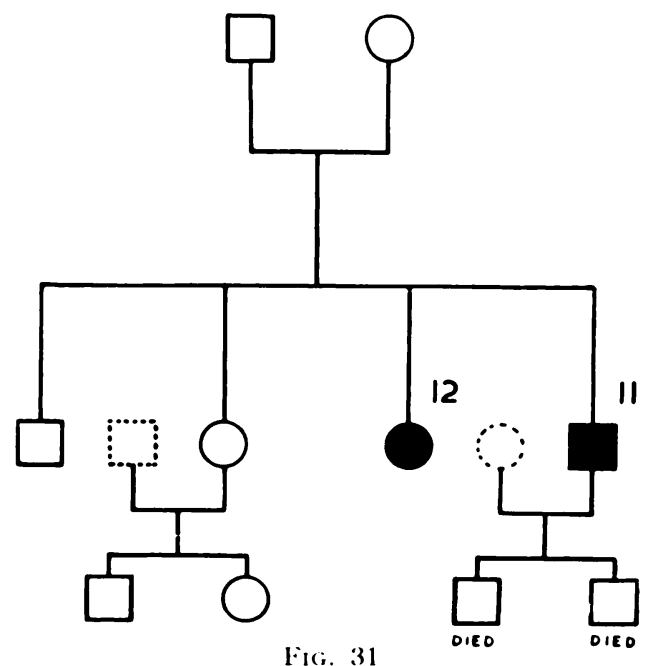

Famile $2 . \quad=$ male: $O=$ female Black affected individuals; white = unaffected individuals. Numerals correspond with case numbers in this report.

Case 11 Man aged forty-three, now disabled and not working. When fourteen he suffered pain in both hips which prevented games. He continued to have pain and stiffness intermittently, but worked as a lorry driver until he was forced to give this up because of pain and stiffness. lie also suffered from pain in the lumbar region, shoulders, knees and ankles. Four years ago he had pain in both wrists and paraesthesia in the hands from compression of the median nerves, which was relieved by division of the flexor retinacula. His two children died in infancy from "asthma" and " pneumonia."

He was thin, $5 \mathrm{ft} .5 \mathrm{in}$. in height, with relatively long upper limbs which nearly reached to his patellae (Fig. 32). Both hands had stubby digits. The left hip was ankylosed in neutral

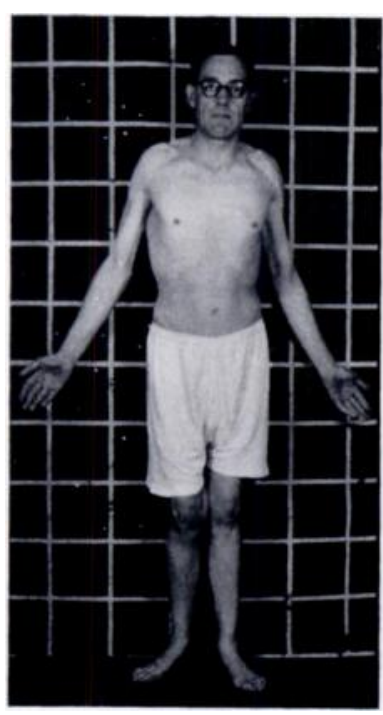

FIG. 32



Fig. 33

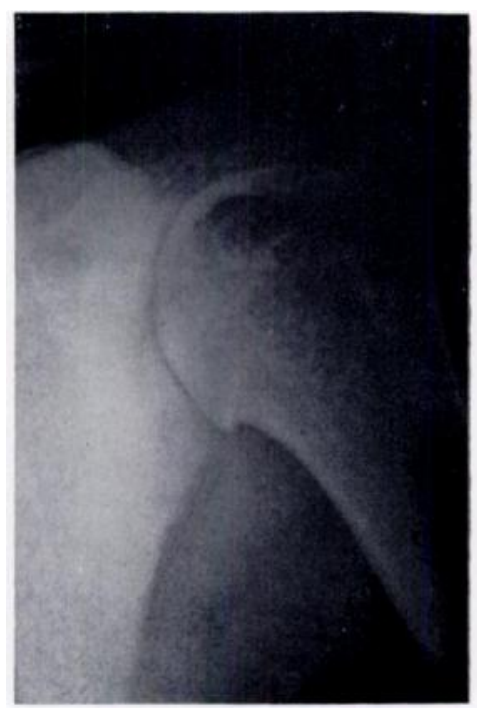

Fig. 34

Case 11. Figure 32-Patient aged forty-three. Figure 33-Left hip. Figure 34-Left shoulder.

vOL. 37 B, NO. 2 , MAY 1955 




FIG. 35



Fig. 36

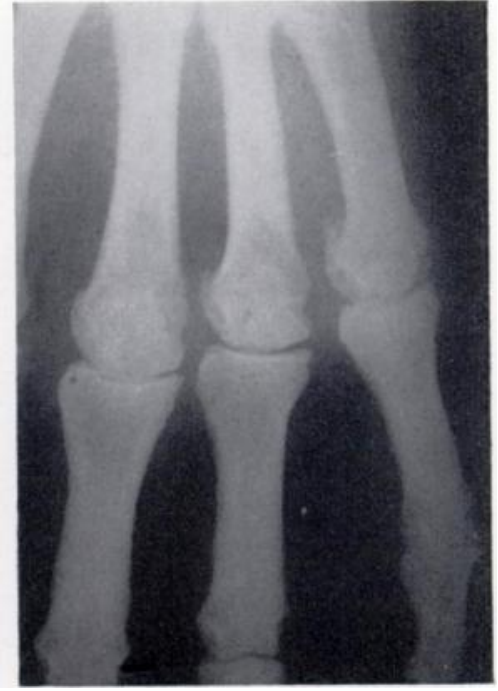

FIG. 37

Case 11. Figure 35-Thoracic spine. Figure 36-Left ankle. Figure 37-Part of left hand.

position. At the right hip a moderate range had been restored by arthroplasty. Both shoulders had a restricted range of movement, total abduction being 90 degrees. At the elbows, wrists and ankles movements were slightly reduced. Radiographs showed severe osteoarthritic changes in the hips (Fig. 33). The shoulders showed cyst formation, flattening of the infero-medial surfaces of the humeral heads and underhanging beaks (Fig. 34). Some of the vertebral bodies were flattened and wedged, particularly T.6-10 (Fig. 35). The lower tibial surfaces were sloping and the left talus was irregular (Fig. 36). The metacarpal and metatarsal heads were flattened (Fig. 37).

Case 12-Woman aged forty-five. From the age of fifteen she had progressive painful stiffness of both hips, which eventually forced her to give up her work as a packer. She also suffered from pain in her shoulders, knees and ankles. Radiographs revealed osteoarthritis in both hips (Fig. 38) and cystic changes in both glenoid fossae (Fig. 39).



FIG. 38

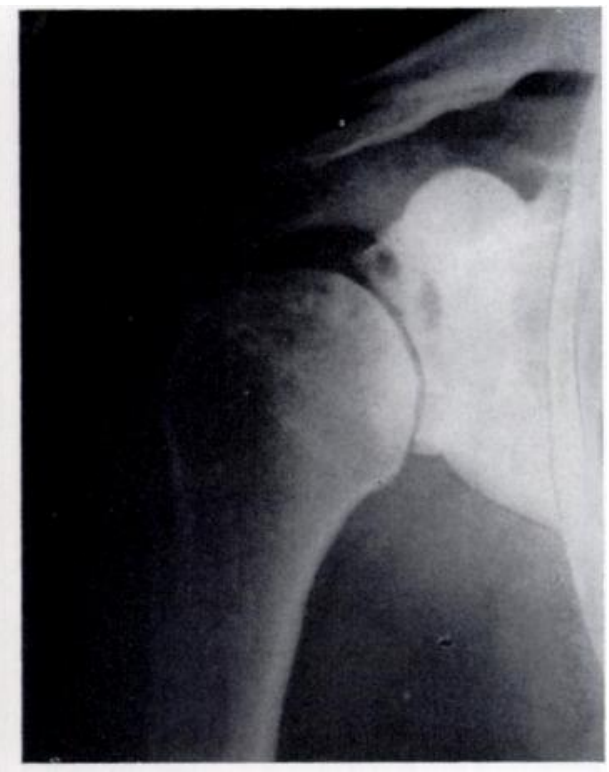

Fig. 39

Case 12. Figure 38-Left hip. Figure 39-Right shoulder.

THE JOURNAL OF BONE AND JOINT SLRGERY 




FIG. 40

Case 13 -Right hip.

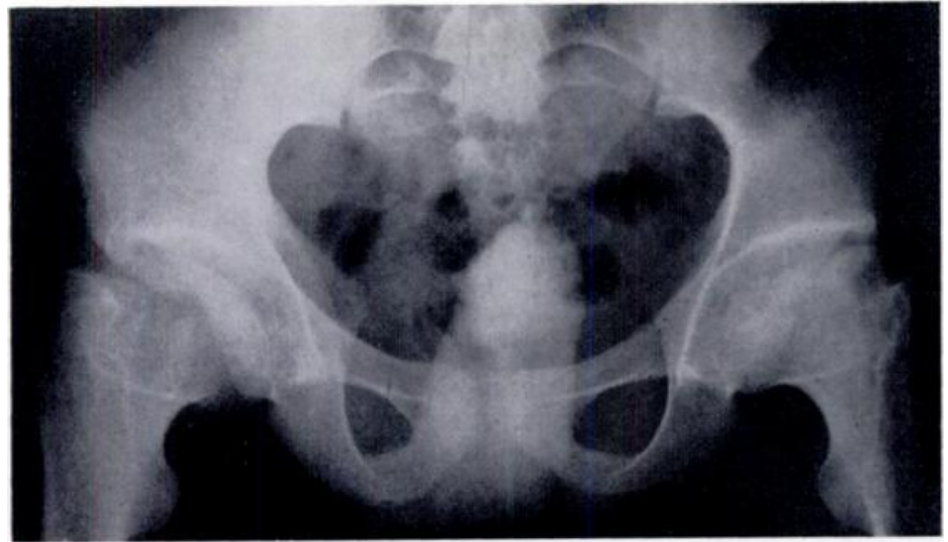

FIG. 41

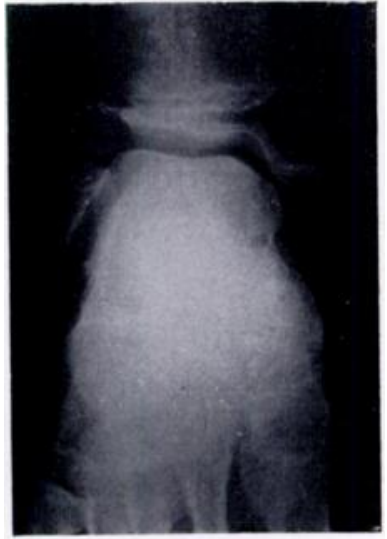

FIG. 42

Case 14. Figure 41-Hips. Figure 42-Right ankle.

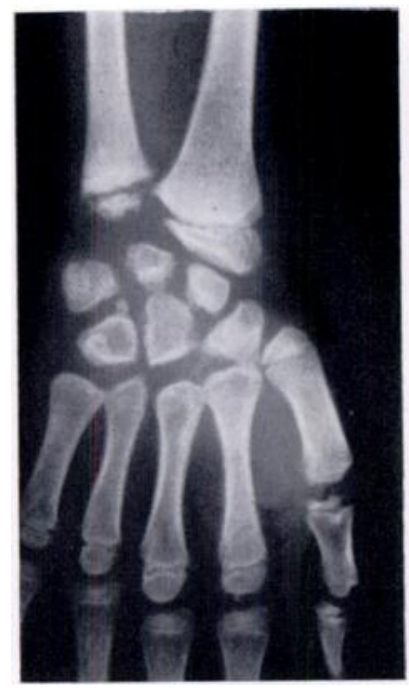

FIG. 43

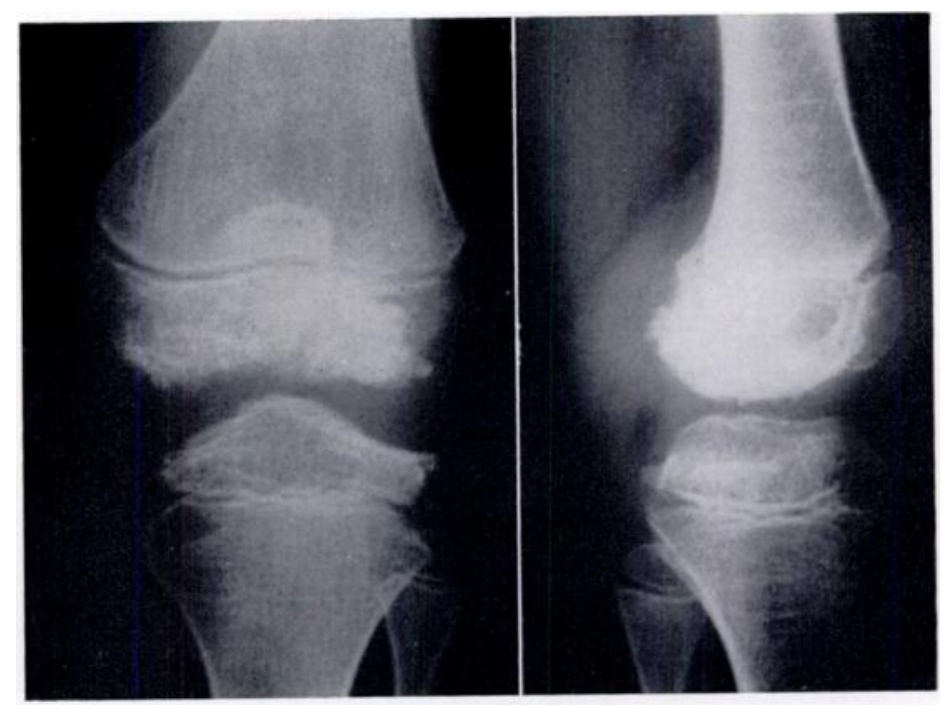

Fig. 44

Case 14. Figure 43-Right hand. Figure 44-Left knee.

พol. $37 \mathrm{~B}$, No. 2, MAY 1955 
FAMILY 3

There are two known cases in this family, details of which have been kindly provided by Mr Norman Roberts. The patient in Case 14 has been previously referred to (Fairbank 1947). In view of a possible family history, the father and brother were examined.

Case 13-Man aged fifty, with two children. He suffered pain in the hips and a limp for most of his life. He was short, and had stubby digits. Movement at both hips was restricted. Radiographs showed osteoarthritis in both hips, with gross flattening of the femoral heads and acetabula with cyst formation and sloping roofs (Fig. 40).

Case 14-Man aged twenty, the younger son of the patient in Case 13. He had pain in the hips for many years. He was short and had stubby hands. Radiographs showed flattening and irregularity of the femoral head and large acetabula (Fig. 41). In previous films (1948) there was deficient development of the lateral part of the lower tibial epiphysis and of both shoulders, knees and wrists (Figs. 42 to 44 ).

\section{DISCUSSION}

Hereditary and familial features-In each of these three families there were two or more individuals affected with this condition. In Family 1 ten out of seventeen members in three generations were affected, including six out of eight siblings (Fig. 1). In Family 2 a brother and sister were affected; further detailed investigation was not undertaken (Fig. 31). In Family 3 a father and at least one son were affected; the rest of the family was not examined. The father was thought by all to be normal until carefully examined and radiographed.

The distribution of the lesions in these three families is not the same, but in each family a similarity could be traced in the affection of its individual members. In Family $l$ there was an obvious hereditary influence, but in Families 2 and 3 this was disclosed only after careful inquiry.

Effect on life and function-There is no record of death from the disease in these families. Infancy - No abnormality was observed by the parents of any of the children: each child sat up, crawled and walked at the appropriate age. Childhood and adolescence-Some of the children complained occasionally of pain in one or other hip, and were unable to walk as far as normal children without tiring. In some cases stiffness in the hips was observed at times, but all these children attended school, and the children of Family 1 participated normally in games. The patient in Case 11, as a child, avoided games on account of pain. No difficulties were encountered when they started work. Adult life-The condition, as a rule, eventually caused considerable disability. All the men in Family 1 were engaged in manual work which appeared well within their powers. The man in Family 2 had to give up his work on account of stiff hips.

Pregnancy did not present difficulty in Family 1. In Case 1 the patient had eight children, and the other two women had two each.

Common features. Dw'arfism-All the affected members of Family 1 were between $4 \mathrm{ft} .6 \mathrm{in}$. and $5 \mathrm{ft}$., in contrast to the unaffected father and son who were $5 \mathrm{ft} .6 \mathrm{in}$. in height.

In Family 2 the two affected members were normal in height-5 $\mathrm{ft} .6 \mathrm{in}$.- though shorter than other members of the family.

The father and son in Family 3 were both said to be short.

Distribution of lesions-In Family 1 the frequency of involvement was, in order: hips, ankles, shoulders, spine, skull. The hands, feet, knees, elbows and wrists were unaffected. In Family 2 the involvement was: hips, shoulders, ankles, hands and spine. The knees, elbows and wrists were unaffected. In Family 3 the involvement was more widespread: hips, shoulders, knees, ankles, hands, feet and elbows. Hands - In Families 2 and 3 the hands were stunted and the digits short, stubby and blunt at the ends. Movements and function were full. In Family 1 there was no abnormality in the hands. Spine - In some members of Families 1 and 2 the trunk appeared short, and the limbs relatively long (Figs. 2, 18 and 22).

Radiographic appearances-Abnormal features occurred only in the epiphyses in children and the joint surfaces in adults. The hip region was affected in all cases. In the children the 
affected epiphyses were late in appearing and backward in development, but fusion was not delayed.

In the adults the lesions varied from a slight irregularity of the shape of the femoral head and acetabular roof to severe coxa plana and irregular acetabula. In no case was subluxation present. Osteoarthritic changes occurred in patients over the age of thirty-five and in one, at least, under that age.

In one of the children (Case 9) there was mild fragmentation of the left upper humeral epiphysis, and, in some of the adults, there was infero-medial flattening of the humeral head and some dysplastic change in the glenoid. At the ankle the lower tibial epiphyses or surfaces were sloping from the lateral to the medial side, and in some there were corresponding changes in the talus.

In the hands and feet of Family 1 there were no abnormalities in the metacarpals, metatarsals or phalanges, whereas in Families 2 and 3 these bones were stunted (Figs. 37 and $4: 3)$.

Comparison with previously recorded cases-Fairbank (1947) gave the name dysplasia epiphysialis multiplex to a condition characterised by mottling or irregularity in density of several of the developing epiphyses, dwarfism and stubby fingers.

In a collected series of twenty-six cases he found a variety of epiphyses involved: most commonly at the hips, shoulders, ankles and hands; less frequently the knees, wrists and elbows. In only two cases was platyspondyly observed.

Hereditary and familial influences were not marked, though a mother and son, two sisters, and boy twins were affected. Radiographically, the abnormalities in the epiphyses were irregularity in ossification, late appearance, and early fusion. The epiphyses were mottled, sometimes mulberry-like, and appeared to have multiple centres. The upper femoral epiphyses were most commonly affected but only rarely were changes seen in the acetabula. There was flattening in the upper humeral epiphyses, but the glenoid fossae were normal. Fairbank found many variations from this common pattern.

Case 8 of this series showed the features of dwarfism and affection of several epiphyses, but there were no recognisable changes in the hands. A rather unusual feature was the well marked hereditary element (Fig. 1). In the affected members of this family there was a relatively high proportion of cases in which the spine was affected, and in some the dwarfism appeared to be of the short-trunk type.

In Family 2 the two affected members were not markedly dwarfed, but characteristic changes were present in the hips, shoulders, ankles and hands. In Case 11 the spine was also involved and the trunk was relatively short. This might well represent a mild reduction in stature, for some of his family were considerably taller.

In Family 3 both father and son had a similar widespread distribution of lesions, but it is not known whether the spine was affected.

Whereas all these fourteen cases thus showed many of the characteristic features of dysplasia epiphysialis multiplex, there are some discrepancies: 1) the hereditary or familial nature of all the cases; 2) involvement of the spine in some cases, causing a short-trunk rather than short-limb type of "dwarfism" in Families 1 and 2 (3 not known); and 3) the mild nature of the affection in Families 1 and 2. Despite these differences, the characteristic features justify the inclusion of these cases in the condition described by Fairbank as dysplasia epiphysialis multiplex. Fairbank (1947) advised that a child below average height suffering from bilateral pseudocoxalgia should have radiographs taken of the shoulders and ankles to exclude this dysplasia. Similarly, bilateral osteoarthritis of the hips in a short person under the age of forty might suggest examination for multiple epiphysial lesions.

Genetic aspects-In Family 1 at least three generations were affected, and ten individuals out of eighteen had the features of this condition. This points to a genetic basis. The defect appears to be due to a Mendelian unifactorial dominant gene. It is unifactorial because the

VOL. $37 \mathrm{~B}$, No. 2, MAY 1955 
affected is clearly distinguished from the unaffected. It is dominant because the ratio approximates to the $1: 1$ ratio expected, and because if recessive it would require that the normal parents marrying into the family were carriers, unlikely in a disease so rare as this. Families 2 and 3 have not been fully investigated, but the occurrence of two cases at least in each family supports the hereditary basis suggested by Family 1.

In previous reported cases there is evidence of an inconstant hereditary basis. Fairbank (1947) collected many cases from those previously classified under different names. Of these, Gardiner-Hill (1937) described two sisters, Barrington-Ward (1912) a brother and a sister, Resnick (1943) a mother and twin boys, Cholmeley (1947) two brothers. Waugh (195:) described the affection in three sisters. Thus twelve reported cases and the fourteen herein described give a familial or hereditary basis in twenty-six out of forty cases.

It is possible that more would have been found to have affected relatives, but many of these individuals do not regard themselves or their relatives as abnormal until complications arise or radiographic examination reveals the condition.

Nature of the affection-The underlying pathology of dysplasia epiphysialis multiplex is a failure of the epiphyses to ossify normally, both in rate and extent. This may express itself in most of the epiphyses or in only a few. The variability in degree and distribution accounts for the diversity of conditions that have been collected under this heading. Some are almost within normal limits whereas others approach the condition described by Morquio and Brailsford as chondro-osteo-dystrophy (Brailsford 1929).

Fairbank (1947) distinguished chondro-osteo-dystrophy from dysplasia epiphysialis multiplex by the characteristic anterior tongue-like prolongations of the vertebral bodies, the angular kyphosis, and the more severe involvement of the epiphyses, particularly the acetabulum. It is worth noting that in Families 1 and 2 there were epiphysial changes in the vertebrae, but no kyphosis and no anterior tongue-like projections. In some members of Family 1 there was slight irregularity of the acetabula.

In gargoylism the dysplastic changes in the epiphyses resemble, more or less, those in Morquio-Brailsford syndrome, but in the former there is involvement of systems other than the musculo-skeletal.

The failure of epiphysial development may also cause other disorders that have not hitherto been classified with dysplasia epiphysialis multiplex, such as " familial brachydactyly associated with bilateral coxitis" (Brailsford 1946).

I am grateful to $\mathrm{Mr}$ Charles Gray for his help in the preparation of this paper. I should also like to thank Mr Norman Roberts for permission to include cases 13 and 14, Miss C. Lucas of the Royal Free Hospital School of Medicine for her advice on the genetic aspect, and Mr J. Sheppard for the photographs.

\section{REFERENCES}

Barrington-Ward, L. E. (1912): Double Coxa Vara with Other Deformities occurring in Brother and Sister. Lancet, i, 157.

Brailsford, J. F. (1929): Chondro-Osteo-Dystrophy (Roentgenographic and Clinical Features of a Child with Dislocation of the Vertebrae). American Journal of Surgery, N.S. 7, 404.

Brailsford, J. F. (1946): Familial Brachydactyly with Associated Bilateral Coxitis. British Journal of Radiology, N.S. 19, 127.

Cholmeley, J. A. (1947): Personal communication to Sir Thomas Fairbank referred to in British Journal of Surgery, 34, 225.

Fairbank, H. A. T. (1946): Dysplasia Epiphysealis Multiplex. Proceedings of the Royal Society of Medicine (Section of Orthopaedics), 39, 315.

Fairbank, Sir T. (1947): Dysplasia Epiphysialis Multiplex. British Journal of Surgery, 34, 225.

Gardiner-Hill, H. (1937): Abnormalities of Growth and Development. British Medical Journal, i, 1,241. Resnick, E. (1943): Epiphyseal Dysplasia Punctata in a Mother and Identical Male Twins. Journal of Bone and Joint Surgery, 25, 461.

Wavgr, W. (1952): Dysplasia Epiphysialis Multiplex in Three Sisters. Journal of Bone and Joint Surgery, 34-B, 82. 